\title{
O DEBATE ENTRE EHRLICH E KELSEN: A CONVERGENCIA FILOSÓFICA ENTRE POSITIVISMO JURÍDICO E SOCIOLOGIA DO DIREITO NO COMEÇO DO SÉCULO $\mathrm{XX}$
}

\section{Danilo Panzeri Carlotti ${ }^{1}$}

\section{Resumo}

O artigo apresenta um resumo do debate entre Ehrlich e Kelsen a respeito de suas propostas metodológicas para a fundação de uma ciência do direito. A tese apresentada neste artigo é que ambos defendem uma limitação a respeito do tipo de debate jurídico que se é possível ter que pode ser associada com uma concepção filosófica positivista a respeito da natureza da linguagem como apresentada por Wittgenstein em seus primeiros trabalhos. O artigo é dividido em cinco partes:

1. Introdução;

2. Delimitação de objeto e implicações metodológicas para a formação de uma "ciência" do direito;

3. 'Normas', empiria e validade;

4. Pontos de convergência com o pensamento de Wittgenstein;

5. Conclusão.

Palavras-chave: positivismo jurídico; sociologia do direito; Kelsen; Ehrlich; Wittgenstein.

\section{INTRODUÇÃO}

O debate entre Kelsen e Ehrlich foi marcado pela busca por definir as bases de uma ciência do direito, seja enquanto uma ciência pura do direito, seja enquanto uma ciência social do direito. No início do século XX, quando este debate ocorreu, vários autores buscavam redefinir as bases do pensamento científico, influenciados pelos desenvolvimentos dos séculos anteriores, em especial tendo em vista os debates patrocinados por cientistas da natureza no século XIX. Foi um tempo de redefinição do tipo de conhecimento que poderia ser aceito academicamente e como ele deveria ser produzido. Tendo em vista o método e objeto próprios ao direito, postula-se uma correspondência significativa, a partir da filosofia da linguagem, entre o debate entre Kelsen e Ehrlich e os debates a respeito dos limites do conhecimento como propostos pelos positivistas, seja os positivistas lógicos ou sociológicos, daquele tempo.

\footnotetext{
${ }^{1}$ Doutorando pela Faculdade de Direito da USP na área de Filosofia e Teoria Geral do Direito. Atualmente é pesquisa dor da Fundação Getúlio Vargas onde desenvolve projetos de natureza aplicada. E-mail: danilopcarlotti@gmail.com vol. 08, nº. 04, Número Especial. Rio de Janeiro, 2015.pp. 2287-2303
} 
Este artigo busca analisar partes do pensamento de Kelsen e Ehrlich através dos principais pontos de divergência entre eles a respeito de suas propostas de fundar uma teoria "pura" e uma "sociologia" do direito. A pureza proposta por Kelsen é uma delimitação da atividade de descrição do direito, entendido como um sistema de signos que se relacionam. O conceito fundamental para a estruturação do direito, segundo ele, é a validade. Ehrlich se propõe a descrever a realidade social tendo objeto de estudo regularidades de comportamento e abstrair, a partir destes comportamentos observados, regras que comporiam o direito "vivo", conceito central de sua teoria, de certa sociedade.

A partir dta análise é possível associá-los com a filosofia de Wittgenstein como exposta em seu Tratado Lógico Filosófico. Wittgenstein teria nesse momento continuado ou dialogado com o projeto filosófico de lógicos como Russel e Frege (KENNY 2006, Cap. 2). Em sua obra, a linguagem é descrita como um conjunto de signos que se relacionam e que servem unicamente para descrever a realidade (KENNY 2006, cap. 4). A realidade seria um conjunto de estado de coisas ou fatos a serem nomeados pela língua (WITTGENSTEIN 2002). Uma filosofia sensata seria uma filosofia que se limitasse a exprimir aquilo que pode ser expresso, representando-o adequadamente e de forma lógica. Uma teoria metafísica seria justamente uma teoria que busca exprimir mais do que é possível, divagando sobre estado de coisas ou fatos de maneira metafórica, imprecisa ou etérea.

O projeto filosófico do positivismo neste período pode ser descrito como a tentativa de "reconstruir racionalmente" vários campos científicos, entre eles, o direito por Kelsen, como exposto por Golding, que associa expressamente Kelsen com esta corrente filosófica. A reconstrução racional seria possível a partir de uma linguagem ideal, identificada com o projeto de Wittgenstein (2002) de representação dos fatos da forma mais lógica possível, de tal maneira que cada fato fosse representado por uma proposição que a ele correspondesse (GOLDING 1971,72).

Segundo Golding $(1971,73)$ Kelsen teria sido inovador no direito seguindo esta tradição em dois sentidos: (i) na maneira de apresentar o que seriam normas jurídicas; (ii) na maneira de estruturar as relações entre normas dentro de um sistema. De certa forma, a busca de Kelsen foi por uma linguagem ideal com a qual seria possível exprimir o direito em qualquer caso e em qualquer contexto, a partir da descrição das situações por normas e pela relação entre as normas organizadas hierarquicamente.

Algo semelhante poderia ser dito a respeito de Ehrlich. Sua concepção de regras enquanto os comportamentos "de fato" foi uma importante oposição à teoria kelseniana e continua uma posição intelectual importante que permite que autores contemporâneos discutam o fenômeno do "pluralismo jurídico" (WOLKMER 2001; SINGH 2010). Sobre uma revisão da literatura da sociologia do direito brasileira e possíveis pontos de contato com o debate como apresentado neste artigo ver Lopes e Freitas Filho (2014). 
Esta associação entre estes autores, nos termos propostos, permite encontrar um fundamental ponto de contato entre as teorias de Kelsen e Ehrlich, identificando-as com uma única concepção de linguagem e, assim, com uma única concepção de realidade observada, apesar das importantes divergências a respeito do método e do objeto da ciência jurídica. Esta reflexão pode auxiliar na compreensão dos debates contemporâneos sobre os métodos e limites de afirmações sensatas que se pode fazer a respeito do direito e da realidade social.

\section{DELIMITAÇÃO DE OBJETO E IMPLICAÇÕES METODOLÓGICAS PARA A FORMAÇÃO DE UMA “CIÊNCIA” DO DIREITO}

A forma como Ehrlich e Kelsen se propuseram a contribuir para uma teoria do direito pode ser resumida a partir das bases sugeridas por eles para a construção de uma ciência jurídica. Apresentam-se agora suas diferentes propostas de delimitação do objeto de conhecimento de uma ciência jurídica e os respectivos métodos para conhece-lo.

Para Ehrlich $(1986,9)$ a ciência do direito deveria obedecer ao desenvolvimento de outras ciências da mesma época, como as ciências naturais, buscando conhecimento a partir da observação dos 'fatos' ou da realidade 'social', deixando de ser uma simples prática que implicava na memorização de atos e procedimentos transmitidos pelo trabalho prático junto ao Judiciário.

Para tornar-se uma ciência, seria necessária a adoção de um método imparcial em relação ao observador e capaz de explicar a 'realidade' ou o conjunto de fatos além da aplicação do direito estatal, concebendo o direito a partir da função que este desempenharia em uma sociedade. Nota-se a preocupação, também das ciências naturais de criar métodos de observação que tornem qualquer afirmação a respeito do objeto de estudo uma conclusão absolutamente independente das características peculiares do observador.

A concepção de direito como unidade da ordem estatal seria uma derivação de uma forma errada de se conceber e ensinar-se o direito (EHRLICH 1986, 22; KLINK 2009, 127) e deveria ser substituída pela ideia do direito enquanto uma ciência social. Somente enquanto ramo da sociologia o direito poderia então ser 'científico' (EHRLICH 1986, 26).

Essa atitude descritiva era tida por fundamental para Ehrlich pela alegada predominância da realidade social sobre o direito, tendo em vista que as mudanças sociais, como mudanças econômicas ou políticas, ocasionariam necessariamente mudanças no direito que, caso não se adaptasse, levaria ao colapso da ordem interna da sociedade (EHRLICH 1986, 47). Em suas próprias palavras (EHRLICH 1986, 49): "Nenhuma associação juridicamente regulada pode existir, apoiando-se exclusivamente em normas jurídicas; ela necessita do constante apoio de normas extrajurídicas que multiplicam e complementam sua efetividade.". Este fato é considerado por ele como absolutamente óbvio. 
Para Kelsen (1999, prefácio) os dois principais elementos que deveriam ser excluídos do pensamento jurídico para a formação de uma teoria jurídica 'pura’ seriam a "ideologia política” e "todos os elementos de ciência natural". Sem eles seria possível o cientista do direito fazer considerações propriamente e unicamente jurídicas a respeito de determinado aspecto da realidade social de maneira imparcial em relação a suas crenças ou preferências particulares.

A ideologia política que visa ser afastada das considerações jurídicas por Kelsen é a pergunta a respeito de qual o direito que melhor corresponde a certo estado de fatos ideais, ou seja, quais as possíveis alterações que o direito positivo deveria sofrer para se adequar a alguma ideologia específica, o que levou Kelsen a ser chamado de "liberal" por conservadores e "fascista" por marxistas de sua época (JABLONER 1998, 376 a 378).

Esta questão da ideologia política no pensamento de Kelsen pode ser melhor compreendida a partir da reconstrução feita por Marramao (2000) do pensamento de Schmitt e da divergência entre ele e Kelsen sobre a relação entre legalidade e legitimidade no começo do século XX.

Um dos pontos fundamentais do debate jurídico nesta época era a discussão sobre o fundamento do direito, ponto central também da teoria de Ehrlich. Schmitt entendia a categoria "decisão" como sendo fundamental para explicar a natureza do que era a soberania política e também o direito. Frente a um caso de exceção ou em casos em que não fosse possível extrair da norma uma decisão para o caso concreto por subsunção, caberia ao soberano decidir sobre como proceder. Esta competência seria o que caracterizaria a soberania. A relação entre legitimidade e legalidade poderia ser melhor explicada por um ato de poder ou, nas palavras de Heller (MARRAMAO 2000, 1577), por uma “vontade sem norma”. A problemática do fundamento do direito para Kelsen o permitiu discutir ao mesmo tempo a estrutura do ordenamento jurídico e apresentar seu projeto de pureza metodológica. O conceito que este autor utilizou para resolver esta problemática foi o conceito de norma fundamental. A norma fundamental seria a norma hierarquicamente superior a todas as outras normas e, desta forma, seria a garantia de validade do ordenamento jurídico (KELSEN 1999, 135 e ss.). Ela seria um pressuposto lógico ou uma categoria a priori que deveria ser utilizada para compreensão da realidade e identificação da ordem soberana válida juridicamente. Esta explicação sobre o fundamento do ordenamento rechaça toda e qualquer consideração sobre o valor moral ou sobre a intenção política dos membros da ordem social, tornando-se assim fonte de validade de todas as normas e uma proteção metodológica a qualquer consideração externa ao direito. Nas palavras de Heller, opositor de Kelsen à época, (MARRAMAO 2000, 1577), uma "norma sem vontade".

Seu método, já à época em que foi escrito, foi considerado por muitos um método "formalista". Kelsen $(1929,77)$ rebatia este argumento afirmando que qualquer método que organiza conceitos é um método formal, por definição. Sua teoria não visava retratar fielmente um sistema jurídico, mas possibilitar a cognição de qualquer sistema jurídico estatal. Para compreendê-los era necessário apreender as características formais dos sistemas 
jurídicos. Desta forma, Kelsen visava a objetividade, impossível de se obter com teorias políticas ou morais de análise do direito e diferente da subjetividade ou vontade que move os legisladores para a criação do direito. A respeito de sua teoria (KELSEN 1929, 78): "Nisto reside a essência da "pureza": no seu desejo de conhecer, não de querer; somente ser acadêmica, não política" (tradução livre). A literatura a respeito do "formalismo" de Kelsen no período em que este escreveu é considerável. Para uma revisão desta literatura ver os trabalhos de Paulson (2005) e Leal (2014). Ambos os autores, em resumo, apresentam uma defesa de Kelsen enquanto defensor de uma ciência descritiva e postulam que esta "pureza" seria uma opção metodológica válida, dentre outras opções possíveis.

A respeito do segundo elemento que deveria ser excluído da ciência jurídica segundo Kelsen, os "elementos de ciência natural", seria necessário separar a "sociedade da natureza e a ciência social da ciência natural" (KELSEN 1999, 53).

As ciências naturais buscariam uma descrição da realidade que se limitaria a considerar "real" aquilo que pudesse ser observado a partir de meios de identificação e prova empíricos independentes do sujeito observador de acordo com as regras de causalidade própria às ciências. Neste sentido (KELSEN 1999, 54) o autor descreve a seguinte situação como exemplo: "quando um metal é aquecido, dilata-se".

Para descrever o direito seria necessária uma forma de descrição da realidade que não pressupõe ou não utiliza o princípio da causalidade. A descrição própria a uma ciência social, como o direito, teria como objeto as condutas normativas de uma sociedade. No caso do direito a causalidade não seria absolutamente estranha, já que para Kelsen a ideia de liberdade enquanto imputação só é possível de ser compreendida em virtude da ideia de causalidade (KELSEN 1999, 118 e ss.), mas, a explicação da conduta humana que tem alguma relação com o direito quando apresentada por juristas deveria considerar o critério de validade para avaliar as normas jurídicas, não o critério de causalidade, para explicar a juridicidade de uma conduta ou a licitude de uma regra. O direito seria um conjunto de regras abstratas que se determinam mutuamente e, portanto, não teria nenhum tipo de correspondência com a realidade empírica, nem com comportamentos regulares observáveis.

A exclusão do método próprio às ciências naturais é uma forma de delimitação de um campo único para a ciência do direito, mas, também é uma oposição a uma forma de compreensão 'sociológica' do direito, nos termos como proposto por Ehrlich, notadamente, a forma de descrição ao máximo "empírica" como proposta.

Esta preocupação com a mera descrição da realidade pode ser associada a uma dicotomia importante e que distinguiu Ehrlich de Kelsen, qual seja, a oposição entre "ser" e "dever-ser". Haveria algo que poderia ser denominado como o mundo do "ser" ou o mundo como descrito ou vivenciado pelos seres humanos. O mundo do "dever-ser" seria a realidade idealizada, quase platônica, do mundo das ideias ou valores, composto por 
avaliações ou projetos de como as pessoas deveriam se comportar ou qual o estado de fatos que se deseja que fosse realidade.

Ambos os autores se valeram desta dicotomia para construir suas teorias. É primeiro necessário apresentar como eles se valeram desta dicotomia e quais acusações foram apresentadas mutuamente por este uso.

Kelsen se propunha a descrever o direito de qualquer sociedade tal como ele era e, neste sentido, ele se opôs como apresentado a descrições valorativas ou morais sobre o direito. De acordo com sua teoria, todo direito poderia ser estruturado enquanto uma série de regras hierarquicamente organizadas que se reportavam umas às outras mutuamente, sendo que regras hierarquicamente superiores seriam a fonte de validade de normas hierarquicamente inferiores. Esta estrutura seria absolutamente independente de qualquer valor ou juízo moral a respeito do conteúdo das normas ou de finalidades do ordenamento. Seu projeto buscaria apresentar bases teóricas para descrever o direito que existia ou o direito como ele "ê" em determinado contexto, contudo, ressaltando sempre que o direito é uma ciência normativa.

A preocupação de Kelsen com a criação de uma ciência capaz de descrever o direito o levou a se opor expressamente a teorias "metafísicas" que não teriam nenhum tipo de correspondência com a realidade e que, portanto, não seriam científicas, nos seguintes termos (Kelsen 2006, 163):

Uma teoria do direito perde seu caráter empírico e se torna metafísica somente se ela extrapola o direito positivo e elabora proposições sobre um direito natural presumido. A doutrina do direito positivo é paralela à ciência empírica da natureza, a doutrina do direito natural à metafísica. (tradução livre).

Esta oposição à metafísica, inclusive, é um ponto de contato entre a sua teoria e o círculo de Viena, como reconhecido pelo próprio Kelsen (JABLONER 1998). Kelsen, reconhece, portanto, um tipo de "paralelo" com ciências naturais que será explorado adiante.

A ideia de "dever" para Kelsen (1999, 82 e ss.) é associada primeiramente com a ideia de dever universal de acordo com a tradição kantiana. Um "dever" no sentido estrito, deste modo, seria uma prescrição categórica a respeito de como um ser humano deveria se comportar em determinada situação. Contudo, como Kelsen rejeita a existência de uma ordem moral superior a qualquer outra, ideia fundamental para a filosofia kantiana, ele vê a existência de "deveres" imutáveis como uma impossibilidade ou uma inutilidade. Impossível, porque não haveria uma única ordem moral a ser seguida, segundo ele. Inútil, porque se há inúmeras ordens morais a afirmação de que alguém deve seguir uma destas ordens não é critério suficiente para explicar ou determinar certo comportamento.

O "dever jurídico" seria um conceito oposto a este tipo de regulamentação moral, já que os deveres jurídicos seriam estabelecidos por normas jurídicas válidas em certo contexto contingente. Mas, para Kelsen, a ideia de "dever" não deve ser entendida como a prescrição de uma conduta, mas a prescrição de uma sanção. A regra jurídica segundo ele teria a característica básica de prever sanções. Em suas palavras (Kelsen 1999, 84): 
“Devido é apenas o ato de coerção que funciona como sanção.". Conforme Golding (1971, 81) quando este analisa o pensamento de Kelsen, "normas jurídicas são distintas de outras normas na medida em que são direcionadas a servidores públicos", ou seja, as normas indicariam não uma conduta devida dos particulares, mas uma conduta devida dos servidores encarregados de punir e vigiar os particulares em caso de descumprimento.

Kelsen acusa Ehrlich de descrever como certas interações ocorrem ou como um estado de coisas "é" em determinado momento, sem levar em considerações os deveres estabelecidos socialmente por um mecanismo reconhecido como válido. Segundo Kelsen, as regras jurídicas válidas não precisavam corresponder a regularidades observadas em nenhum contexto. Uma regra continuaria existindo enquanto um "dever" mesmo na ausência de cumprimento regular. Em outras palavras, o método proposto por Ehrlich de observação da realidade seria incapaz de descrever as obrigações dos indivíduos que viveriam sob a égide de um determinado ordenamento jurídico, limitando-se, segundo Kelsen, a observar a sociedade sem poder orientar de nenhuma forma a decisão jurídica estatal sobre casos. Kelsen teria acusado Ehrlich e esta forma de pensar de se limitar a buscar descrever o mundo da mesma forma como os físicos buscavam outrora estabelecer "leis" para descrever os fenômenos naturais (KELSEN 2006, 162; 1911, 58).

Para Ehrlich era fundamental a observância das sociedades tais como elas se apresentavam de fato em determinado contexto. A isto ele opunha o direito estatal que parecia criar um mundo alternativo ou um mundo ideal de "deveres" que não correspondia aos comportamentos regulares observáveis quase que empiricamente.

Como destacado por Carrino $(1992,7)$ a oposição de Ehrlich a teorias que identificavam o direito com o direito estatal se justifica pela sua proposta de explicar com sua teoria a realidade de locais periféricos ou não centrais dos Estados como a Bucovina de seu tempo, onde vivia uma série de povos diferentes que viviam sob regras costumeiras únicas e compondo grupos sociais tão restritos que dificilmente poderia ser dito que eram todos regidos pelo mesmo conjunto de regras estatais. O pluralismo jurídico em regiões onde não havia um Estado fortalecido e centralizado, como a realidade que teria sido percebida por Kelsen seria uma questão para Ehrlich empiricamente observável.

Contudo, Ehrlich tinha uma concepção de regra enquanto obrigação de se comportar de determinada forma, mas, contrariamente a Kelsen, esta obrigação tinha como fonte as relações sociais e não as atividades estatais de positivação do direito. Ehrlich alega que uma "obrigação social" é um tipo de regra vinculante ao comportamento das pessoas.

Não há como distinguir o projeto de Ehrlich de explicar o que seria o "ser" e o "dever-ser" do direito sem levar em consideração sua teoria sobre as 'fontes do direito'.

Haveria uma supremacia de fontes sociais, como a economia, a política, a cultura, ou seja, a totalidade de interações sociais, sobre quaisquer outras fontes institucionalizadas. A compreensão das fontes sociais de 
obrigações vinculantes como sendo exclusivamente 'jurídicas' incorreria no equívoco do jurista que se limita a observar a realidade como se o direito fosse essencial e necessário para que organizações, como as famílias, se mantenham unidas ou mesmo que funcionem (EHRLICH 1986, 69). Esta seria o "dever-ser" ilusório que Kelsen, entre outros, defenderiam. De acordo com esta linha de pensamento, haveria uma incapacidade de concepção da convivência humana sem recurso a normas jurídicas, o que é firmemente repudiado por ele.

O foco de uma teoria de fontes do direito deveria ser buscar as "forças que impulsionam o desenvolvimento das instituições jurídicas" (EHRLICH 1986, 70). Somente quando e na medida em que determinado fato ou comportamento passasse a ter algum papel na lógica de funcionamento empiricamente observável de certa sociedade é que a sociedade poderia então optar por combatê-lo sistematicamente ou incorporá-lo a seu funcionamento. Quando, e somente quando, isto ocorresse é que seria possível a transformação de um comportamento em relação social e, então, em relação jurídica.

Ehrlich teria respondido a Kelsen alegando uma reconstrução equivocada de seu pensamento por este, conforme reconstrução deste debate por Klink (2009, 129 e ss), mas, infelizmente, sem se aprofundar em respostas mais substantivas.

\section{'NORMAS', EMPIRIA E VALIDADE}

É fundamental notar como ambos os autores se propõe a descrever a realidade em oposição às teorias metafísicas ou aquelas que se desligariam do mundo e se tornariam puros devaneios que não poderiam ser comprovados, nem testados e sobre os quais não poderia haver uma discussão racional. Esta limitação sobre a sensatez de possíveis acordos e desacordos sobre o mundo remete à discussão a respeito do sentido das normas jurídicas e os tipos de discussão possíveis sobre elas.

"Normas' são apresentadas por Ehrlich como "realidades sociais" ou "fatos do direito" (KLINK 2009, 128). Elas seriam um tipo de fator "determinante" para a conduta humana reconhecida por um conjunto de pessoas que se relacionam mutuamente na forma de uma organização ou associação e que agem "em geral, de fato" de acordo com elas (EHRLICH 1986, 35). Somente as obrigações ou proibições poderiam ser denominadas "normas". Neste sentido, as regras jurídicas seriam somente mais um tipo de regras neste emaranhado de proibições que inclui proibições religiosas, costumeiras, morais, da moda e etc. A diferença entre as normas jurídicas e as outras normas para este autor seria somente uma questão de "intensidade do grau de sentimento psicológico e social" com relação às normas (CARRINO 1992, 21).

A sociologia do direito teria como tarefa identificar quais as normas que contribuiriam para a organização social, independentemente se elas serviriam ou não como parâmetro para a decisão estatal (EHRLICH 1986, 37). Somente desta forma é que a sociologia do direito seria capaz de se ater à descrição dos "fatos" da realidade social 
ou dos "componentes externos que condicionariam o direito", termo utilizado por Ehrlich para identificar sua semelhança com o projeto iniciado por Montesquieu (EHRLICH 1916).

O sentido das regras, portanto, é identificado com regularides de comportamentos observáveis que, para os membros de certa comunidade, representam ações devidas, proibidas ou permitidas pelo grupo social. Nada há mais que investigar salvo o sentido daquele ato naquela sociedade, se identificado enquanto um ato de coesão social e obrigatório para a comunidade.

A norma jurídica, de acordo com a teoria pura de Kelsen (1999, 2 e ss.), seria um esquema de interpretação da realidade atribuindo a um fato ou estado de coisas um sentido objetivo estabelecido pela norma jurídica. Haveria dois tipos de sentido possíveis de serem atribuídos às ações humanas em sociedade: subjetivo e objetivo. O sentido subjetivo é o sentido atribuído de acordo com a vontade, intenção e intelecção das partes que participam do ato. Por exemplo, alguém pode fazer um contrato com outra pessoa na esperança de ganhar sua confiança para futuros contratos ou por considerar que a realização deste contrato é uma obrigação moral. Haveria um sentido objetivo capaz de ser atribuído pelas normas jurídicas. O sentido objetivo é um significado atribuível à ação ou às ações de estabelecido pelas normas jurídicas através da linguagem. Portanto, em certo momento e local apropriado a assinatura de um papel que contenha determinadas palavras é considerada a realização de um contrato de acordo com o direito. É irrelevante qual a intenção pessoal ou o sentido moral daquele ato, ao menos para o direito.

Nota-se como o sentido da ação é arbitrariamente estabelecido e há uma correspondência direta entre o fato e a linguagem utilizada para representar o fato. $\mathrm{O}$ direito enquanto um conjunto ideal de normas, da mesma forma como uma linguagem perfeita capaz de descrever qualquer estado de fatos ou coisas, ideal positivista da época, deveria ser capaz de adequadamente prescrever um sentido objetivo para qualquer situação, prevendo a correspondente ação devida dos agentes do Estado.

A prática de aplicação do direito, contudo, leva Kelsen a fazer ressalvas a este projeto. Nem todos os casos encontram-se perfeitamente representados pelas normas jurídicas estatais aprovadas pelos órgãos legislativos dos respectivos estados. Havia e há ainda uma distância enorme entre a racionalidade dos doutrinadores e a racionalidade dos políticos responsáveis por legislar. Kelsen é obrigado, portanto, a enfrentar o problema da interpretação. Como garantir uma decisão de acordo com o direito e o sistema de regras válido em todos os casos, mesmo nos casos em que a regra não é representativa da situação real?

A teoria da interpretação de Kelsen (1999, cap. 8) apresenta categorias para se analisar o processo de tomada de decisão de agentes estatais investidos da função jurisdicional. Interpretação seria o ato de decidir, no caso concreto, qual a ação estatal correspondente tendo em vista uma situação fática. Haveria correspondência 
com o "sentido das normas" somente na medida em que a linguagem apresenta, para o magistrado, uma "moldura" que limita seu processo de escolha.

Segundo Kelsen, estes agentes seriam responsáveis pela interpretação do direito observando o sentido das normas ou o significado das palavras constantes da constituição ou das leis, decretos ou normas jurídicas em questão. Há uma diferença importante entre a interpretação destes agentes e a interpretação de, por exemplo, doutrinadores. Os magistrados teriam o monopólio da decisão juridicamente vinculante e, neste sentido, sua interpretação seria "autêntica" ou juridicamente mais importante que a de outros. Doutrinadores, por sua vez, seriam capazes de interpretar o direito. Mas, tendo em vista o fato de que a interpretação deles não é vinculante, suas opiniões são consideradas por Kelsen como interpretação "inautênticas", ou seja, meras opiniões que podem ou não orientar os únicos responsáveis por, metaforicamente, "dizer" o direito no caso concreto (KELSEN 1999, cap. 8).

Esta aplicação do direito pelos magistrados corresponde a ação do agente deveria julgar se o caso concreto corresponde a alguma previsão em abstrato do ordenamento. Se F, então S, ou seja, se há uma norma que prevê que se "Fato", então "Sanção", e o magistrado é capaz de constatar a existência de determinado "Fato" de maneira inequívoca, ele deve ordenar a aplicação da sanção como prevista em norma. Mas e quanto aos casos difíceis, sobre os quais teorizou, entre outros, Herbert Hart?

Haveria um poder fundamental atribuído ao juiz, inerente à sua posição de autoridade, o poder de decidir nestes casos de maneira vinculante. A moldura kelseniana é uma delimitação das possíveis interpretações do magistrado, mas o direito não seria capaz de prever uma aplicação mecânica da norma. A lógica formal não seria suficiente, tendo em vista a natureza necessariamente incompleta do conjunto de regras emanadas do legislativo. Portanto, a interpretação do direito autêntica, ou seja, a interpretação do direito quando realizada por agentes estatais autorizados e a quem se confere a competência de aplicar o direito, é arbitrária, mesmo que delimitada, já que há restrições à liberdade de aplicar o direito, mas Kelsen não apresenta nenhum critério que o intérprete deveria observar na ausência de uma representação clara e inequívoca dos fatos no texto normativo.

A delimitação metodológica proposta pelos autores, bem como sua visão sobre a o sentido das regras jurídicas impõe uma delimitação ao tipo de debate sensato que supostamente é possível ter sobre o direito. Não é possível, de acordo com estes autores, discutir questões metafísicas. Enquanto para Ehrlich isso incluía até o direito estatal enquanto fonte única de direito, para Kelsen isso extrapolava para excluir da teoria jurídica a questão da justiça e todo debate moral sobre a natureza do direito. Não é possível discutir nada além do direito existente em determinadas sociedades, ao menos não no âmbito de uma ciência do direito. Qualquer especulação de cunho moral ou sobre a justiça de determinada regra ou ordenamento não seria, portanto, científica e seria, assim, sem sentido. 


\section{PONTOS DE CONVERGENCIA COM O PENSAMENTO DE WITTGENSTEIN}

Há duas razões pelas quais Wittgenstein foi escolhido como autor central para contextualizar o debate entre Kelsen e Ehrlich. Em primeiro lugar, Wittgenstein foi um importante expoente do positivismo lógico desenvolvido no começo do século XX, tendo contribuído de maneira significativa com as discussões do círculo de Viena. Enquanto tal, suas ideias são representativas do contexto filosófico em que debateram Kelsen e Ehrlich. Em segundo lugar, Wittgenstein é também representativo de uma mudança, a virada hermenêutica na filosofia da linguagem, que representa um conjunto de ideias fundamentais para o desenvolvimento de teorias jurídicas como a de Herbert Hart. É notório que Wittgenstein apresenta em suas obras posteriores, em especial Investigações Filosóficas, ideias sobre a natureza da linguagem que diferem de seus trabalhos iniciais. Contudo, é possível conceber, como o faz McGinn (2006: 2), autora adotada como intérprete central do trabalho de Wittgenstein, que suas concepções iniciais têm um papel a ser reconhecido em sua filosofia posterior, o que reforça ainda mais a importância e representatividade deste autor tendo em vista este período e os debates que o seguiram.

Antes de apresentar resumidamente as peculiaridades e as ideias fundamentais de Wittgenstein desenvolvidas em seu Tratado Lógico Filosófico, é importante destacar visões de outros autores sobre o significado do "positivismo", lógico, filosófico que se desenvolveu no começo do século XX.

Russel define o positivismo lógico a partir de uma referência a seu método, postulando também uma complementaridade entre os métodos empíricos e lógicos (Russel 1950:3): “Logical positivism” is a name for a method, not for a certain kind of result. A philosopher is a logical positivist if he holds that there is no special way of knowing that is peculiar to philosophy, but that questions of fact can only be decided by the empirical methods of science, while questions that can be decided without appeal to experience are either mathematical or linguistic."”. Os aspectos "empírico" e "lógico" da realidade são complementares na análise dos positivistas, segundo Russel. Não há conflito entre estas análises, ao menos para estes autores, sendo possível realizá-las ambas a partir de um arcabouço conceitual fundamental.

É interessante notar que, apesar da convergência filosófica proposta por este trabalho no debate analisado, Ehrlich defende um método exclusivamente empírico de descrição do direito, enquanto Kelsen defende um método que poderia ser denominado como exclusivamente "linguístico", já que preocupado com relações entre signos, ou seja, entre a validade de normas jurídicas.

A união entre empiricismo e pensamento abstrato a partir do raciocínio lógico é também destacado por Blumberg e Feigl tendo como referência fundamental o trabalho de Wittgenstein. Todo conhecimento sobre a realidade deveria ser expresso a partir de regras bem definidas de modo a não se expressar algo para além do mundo. No mesmo sentido que outros autores citados, proposições "metafísicas" não seriam falsas, já que elas não 
teriam qualquer sentido (Blumberg e Feigl 1931: 282). O destaque aqui, assim, é na oposição do positivismo lógico a visões de mundo racionalistas ou outras formas de "misticismo" segundo os autores desta época.

A respeito do que significaria "lógica” para os autores positivistas desta época ver artigo de Ruja em que há uma revisão da literatura sobre positivismo lógico, com ênfase especial no trabalho de Carnap, entre outros. Em suas palavras, Ruja (1936: 400) assim o resume: "Logic may be described as the science of implicatory relationships between propositions".

A filosofia de Wittgenstein exposta em seu Tratado lógico filosófico pode ser resumida como a proposta de um meio para, filosoficamente, identificar problemas com proposições e se determinar se, por um lado, é necessário esclarecer uma proposição sujeita ao debate ou se, de fato, a proposição não é sensata ou não "diz nada" que faça sentido (MCGINN 2006: 10). McGinn não concorda totalmente, contudo, com esta posição, apesar de reconhecê-la. Segundo a autora (MCGINN 2006: 12, 17) a tarefa de Wittgenstein nesta época já é, fundamentalmente, explicar como a linguagem funciona e lidar com seu "grande problema", qual seja, a natureza lógica de proposições de qualquer natureza.

Tendo em vista a complexidade da filosofia de Wittgenstein, selecionou-se um tema fundamental de sua obra desta época como contribuição para esclarecer o presente debate: sua teoria sobre o "significado" das palavras, e sua correspondência com o mundo, e sobre a estrutura lógica de todas as proposições.

Anscombe $(1959,17)$ resume a teoria de Wittgenstein sobre o significado a partir de um comentário à tradução da palavra 'Bedeutung', que foi traduzida como 'sentido' ou 'meaning' por alguns autores. Esta é uma tradução que não corresponde ao significado e à filosofia do primeiro Wittgenstein. As palavras, nesta tradição, se "referem" a algo. Esta referência nada mais é do que uma representação ou, metaforicamente, ocupar no discurso o lugar que o fato ocupa no mundo. Quanto às proposições, de qualquer natureza, a filosofia dos primeiros trabalhos de Wittgenstein previa que uma proposição que não tinha correspondência com algum estado de fatos no mundo não seria nem verdadeiro, nem falso, seria algo sem sentido (KENNY2006, 50; ANSCOMBE 1959, 17).

Esta visão de Anscombe, segundo McGinn (2006: 75) é compartilhada por outros autores como Diamond e Conant. McGinn não nega a importância desta ideia para compreender a filosofia do Tractatus, mas, considera que ela é uma pré-conceito de Wittgenstein nesta época e que o verdadeiro problema central é o de clarificação da natureza lógica das proposições (MCGINN 2006: 77): "Ele deve tornar claro o status universal e apriorístico da lógica" ("He must make perspicuous the universal and a priori status of logic"). As etapas do projeto de Wittgenstein seriam esclarecer como proposições expressam julgamentos sobre o mundo, a relação entre proposições sensatas e proposições lógicas, a relação entre proposições e nomes e a relação entre proposições que permitiria a inferência de algo verdadeiro a partir de um conjunto de proposições. 
Segundo McGinn Wittgenstein é bem sucedido em criar uma representação lógica do funcionamento da linguagem, entretanto, ele só teria sido capaz de fazê-lo justamente porque ele teria idealizado de tal forma a proposição e o sentido que sua teoria se adequou com perfeição. Contudo, ele não teria conseguido representar adequadamente o funcionamento da linguagem, mas somente da linguagem ideal pressuposta no trabalho (MCGINN 2006: 78).

Enfim, a respeito das "imagens" e como elas representariam a realidade, McGinn (2006: 91) afirma que a relação entre a imagem e a situação representada é uma relação lógica. Para compreender o significado de uma "imagem", portanto, seria necessário entender as regras a partir das quais seria possível dizer que a realidade corresponde ou não à certa representação. Caso corresponda, a imagem seria verdadeira, do contrário, falsa.

A partir destas breves considerações é possível, enfim, relacionar a teoria de Wittgenstein diretamente com o debate entre Kelsen e Ehrlich como exposto neste artigo.

Na primeira parte do artigo apresentou-se as limitações metodológicas de Kelsen e Ehrlich que têm grande correspondência com as limitações do positivismo lógico do começo do século tendo em vista o rechaço de teorias "metafísicas" que não teriam correspondência com fatos da realidade. Ambos autores, a sua maneira, buscavam descrever a existência real do "direito", seja na forma de normas jurídicas positivadas por uma autoridade estatal, seja enquanto conjunto de relações sociais. Ambos autores buscaram a construção de uma linguagem objetiva, capaz de ser denominada "científica" de acordo com os padrões de sua época.

A convergência que se propõe é que ambos buscaram limitar os debates sensatos a respeito do direito. Não há espaço para considerações sobre o que deveria ser feito para além do que já existe "na realidade", das normas ou das relações sociais. Mas, até que ponto normas e considerações sobre os fatos bastam e deveriam bastar para se justificar uma decisão jurídica? Até que ponto a linguagem é clara o suficiente ou os fatos passíveis de serem observados com objetividade? Da mesma forma que Wittgenstein, parece que suas teorias parecem se adequar tão bem a seus objetos pela idealização que se faz deles.

A ideia de "significado" de Wittgenstein neste período, resumida como a relação do signo com algo na realidade mediado por regras que determinam as condições de verdade de proposições, também pode e deve ser associada ao debate entre Kelsen e Ehrlich para sua melhor compreensão.

Kelsen com seu conceito de validade jurídica consegue criar uma estrutura fechada que abrangeria todas as normas jurídicas de determinada ordem. As normas jurídicas em si não seriam nem verdadeiras nem falsas. Uma obrigação não seria falsa por não corresponder a alguma ordem superior, divina ou racional. Elas seriam válidas ou inválidas, somente. Seria possível, contudo, fazer afirmações verdadeiras ou falsas sobre o direito, na forma de proposições do tipo "A norma N é válida". 
Ehrlich com sua ideia de "direito vivo" e sua teoria sobre as fontes sociais busca estruturar o direito de maneira diferente. As interações sociais e relações de poder gerariam "fatos" que dariam suporte para as instituições jurídicas. Os signos jurídicos "sensatos" pode-se dizer, assim, deveriam corresponder à realidade propriamente social, devendo-se levar em consideração os fatores políticos, econômicos e outros citados por este autor para se asseverar se, por exemplo, existiria ou não uma obrigação ou regra “N”. Qualquer consideração sobre a melhor decisão, do ponto de vista moral ou ético, ou sobre a decisão mais justa seria uma proposição "metafísica".

\section{CONCLUSÃO}

Apresentou-se neste artigo a tese de que Kelsen e Ehrlich poderiam ser associados com a filosofia dos primeiros trabalhos de Wittgenstein e que isto os levou a propor restrições de ordem metodológica à "ciência do direito", cada qual em sua forma. Apesar das diferenças, tendo sido algumas delas apontadas neste trabalho, esta concepção de linguagem une de certa forma o positivismo jurídico de Kelsen e a proposta de sociologia do direito de Ehrlich. Esta convergência aproxima, do ponto de vista de pressupostos filosóficos, o positivismo jurídico e a sociologia do direito como pensadas no começo do século XX.

Há duas importantes outras considerações sobre esta convergência a serem, enfim, ressaltadas.

Em primeiro lugar, esta forma de conceber e analisar o direito pode ser identificada com um tipo de teoria das normas (LOPES 2009), ao menos a tradição kelseniana. O estudo do direito deveria se limitar a estudar regras que determinam ou deveriam determinar as decisões, seja de agentes privados, seja de agentes públicos. Apesar de pouco intuitivo, acredito possível associar a sociologia jurídica do começo do século com esta tradição na medida em que sua narrativa é muitas vezes determinista, sendo que os fatos sociais não são somente fonte do direito mas determinariam o comportamento dos agentes sociais.

Enquanto teorias que estruturam conceitos elas podem ser mais ou menos satisfatórias, mas, elas falham em adequadamente representar o sentido da ação de seguir o direito, o que remete ao trabalho de Hart e a tradição hermenêutica por ele iniciada. Estas teorias não conseguem adequadamente representar o ponto de vista interno daquele que busca se orientar de acordo com o direito. Ademais, elas só conseguem explicar o comportamento ou apresentar uma orientação sobre o que deve ser feito quando há regras ou fatos suficientemente claros e objetivos.

Em segundo lugar, a adesão a estas formas de pensamento impossibilita para o jurista qualquer discussão sensata a respeito da relação entre moral, justiça e direito. No caso de Kelsen (1998), esta limitação foi expressa em sua obra. Esta é uma limitação que implica em decisões sem critério, ao menos nos casos difíceis, ou em todos os casos em que não há um comportamento expressamente previsto pela norma jurídica a ser seguido por 
particulares ou servidores do Estado. Neste sentido, ambas as propostas se complementam para restringir debates sensatos sobre a aplicação do direito.

Mas por que razão estas limitações são necessariamente pejorativas e não escolhas metodológicas justificadas?

Como ressaltado por Lopes $(2009,53)$ o ato de interpretação não é explicado em ambas as tradições como um ato racional, mas é apresentado como um ato de "vontade", mesmo que limitado em partes pela "moldura" que a linguagem da norma supostamente impõe a quem decide ou pela sociedade, cuja primazia sobre a produção estatal do direito.

Se não é possível ter discussões sensatas sobre a aplicação do direito nos casos em que não há previsão de uma norma específica sobre um comportamento proibido, permitido ou prescrito, toda liberdade de decisão dos magistrados torna-se exercício arbitrário de poder. E, se a decisão dos magistrados é entendida como o exercício de fato de um poder concedido pelo Estado, não há razões para seguir o direito, somente incentivos egoístas da busca por evitar sanções.

Teorias hermenêuticas, de autores como MacCormick, Dworkin, entre outros, fazem frente justamente a estes desafios e parecem ter avançado, a partir das ideias de interpretação, no caso de Dworkin, e razão prática, no caso de MacCormick, o debate para novas fronteiras já vislumbradas nas últimas obras de Wittgenstein.

\section{THE DEBATE BETWEEN EHRLICH AND KELSEN: THE PHILOSOPHICAL CONVERGENCE BETWEEN LEGAL POSITIVISM AND SOCIOLOGY OF LAW AT THE BEGINNING OF THE TWENTIETH CENTURY}

\footnotetext{
Abstract

The article presents a summary of the debate between Ehrlich and Kelsen about their methodological proposals for the foundation of a science of law. The thesis presented in this paper is that both argue of a limitation as to the type of legal debate that you can have, that can be associated with a positivist philosophical conception about the nature of language as presented by Wittgenstein in his early work. The article is divided into five parts:

i. Introduction;

ii. Delimitation of object and methodological implications for the formation of a "science" of law;

iii. 'Standards', empiricism and validity;

iv. Points of convergence with the thought of Wittgenstein;

v. Conclusion.
}

Keywords: legal positivism; sociology of law; Kelsen; Ehrlich; Wittgenstein. 


\section{REFERÊNCIAS BIBLIOGRÁFICAS}

BLUMBERG, AE., FEIGL, H. (1931) Logical positivism. The journal of philosophy. Vol. 28, n 11, pp. 281-296.

CARRINO, A. (1992) Scienza giuridica e sociologia del diritto. Napoli: Edizioni Scientifiche Italiane.

EHRLICH, E. (1986) Fundamentos da sociologia do direito. Brasília, UnB.

(2005) Escritos sobre Sociologia y Jurisprudência. Madrid-Barcelona: Marcial Pons.

(1916) Montesquieu and sociological jurisprudence. Harvard Law Review, Vol. 29, No. 6 (Apr., 1916),

pp. 582-600

GOLDING, MP. (1971) Kelsen and the concept of 'legal system'. In SUMMERS, RS. (ed.) More essays in legal philosophy. Berkley e Los Angeles: University of California Press.

JABLONER, C. (1998) Kelsen and his circle: the Viennese years. In European Journal of International Law 9. P. $368-385$.

KELSEN, H. (2006) General Theory of Law and State. Cambridge: Harvard University Press.

(1929) Legal formalism and the pure theory of law. In JACOBSON, AJ. SCHLINK, B. Weimar: A jurisprudence of crisis. Trad. Berlinda Cooper. Berkley, Los Angeles e London: University of California Press.

(1911) On the borders between legal and sociological method. In JACOBSON, AJ. SCHLINK, B. Weimar: A jurisprudence of crisis. Trad. Berlinda Cooper. Berkley, Los Angeles e London: University of California Press.

(1998) O que é a justiça? A justiça, o direito e a política no espelho da ciência. Trad. Luís Carlos Borges. São Paulo: Martins Fontes.

(1999) Teoria Pura do direito. 6. ed. São Paulo: Martins Fontes.

KENNY, A. (2006) Wittgenstein. Oxford: Blackwell Publishing.

LOPES, JRL. (2009) Entre a teoria da norma e a teoria da ação. In: Storck, Alfredo Carlos; Lisboa, Wladimir Barreto. (Org.). Norma, moralidade e interpretação: temas de filosofia política e direito. 1ed. Porto Alegre: Linus Editores, v. 1, p. 43-80.

LOPES, JRL; FREITAS FILHO, R. (2014) Law and society in Brazil at crossroads: a review, Annual review of law and social science, v. 10, p. $91-103$.

LEAL, F. (2014) O formalista expiatório: leituras impuras de Kelsen no Brasil, Revista Direito GV, v. 10, p. 245268.

MARRAMAO, G. (2000) The exile of the nomos: for a critical profile of Carl Schmitt, Cardozo Law Review, v. 21, n० 5-6.

MCGINN, M. (2006) Elucidating the Tractatus: Wittgenstein's early philosophy of logic and language. Oxford: Oxford University Press.

PAULSON, SL. (2005) Some issues in the exchange between Hans Kelsen e Erich Kaufmann. Scandinavian studies in law, no 48, p. 269-290. 
POUND, R. (1922) An Appreciation of Eugen Ehrlich. Harvard Law Review, v. XXXVI, 1922, n.2.

(1912) The Scope and Purpose of Sociological Jurisprudence, Harvard Law Review, v. 24, n. 8, 191 1; v. 25, n. 2, 1911; v. 25, n. 6.

RUJA, H. (1936) The logic of logical positivism. The Journal of Philosophy, vol. 33, nº 15, pp. 393-408.

RUSSEL, B. (1950) Logical positivism. Revue Internationale de Philosophie, Vol. 4, no 11, pp. 3-19.

SINGH, S. (2010) Eugen Ehrlich's 'Living Law' and its Legacy for Legal Pluralism. Working paper. University of Cambridge. Último acesso em 02.01.2014. Disponível em: http://papers.ssrn.com/sol3/papers.cfm?abstract_id=1660606.

WITTGENSTEIN, L. (2002) Tractatus logico-philosophicus. Trad. D. F. Pears e B. F. McGuinness. London e New York: Routledge Classics.

WOLKMER, AC. (2001) Pluralismo jurídico: fundamentos de uma nova cultura no direito. $3^{\mathrm{a}}$ ed. São Paulo: Editora Alfa Ômega.

Trabalho enviado em 22 de julho de 2015.

Aceito em 06 de setembro de 2015. 